\title{
Contrastive Analysis on Investment Ability of Sunshine Private Funds and Publicly Offered Funds Based on TM - FF4 Model
}

\author{
Yuanyuan Jiang \\ School of Economics, Shanghai University, Shanghai, 200444, China \\ 18800206187@163.com
}

Keywords: Publicly offered funds; Sunshine private funds; Investment ability; TM-FF4

\begin{abstract}
This article mainly uses the TM - FF4 model to compare the stock selection ability and market-timing ability of sunshine private funds with that of publicly offered founds. In practical analysis of 58 founds in 2015, we use the method of the bootstrap and probability of success respectively as auxiliary inspection. The result shows that sunshine private funds managers' timing ability is only marginally better than publicly offered funds managers', but their stock selection ability is much lower than that of the publicly offered funds managers.
\end{abstract}

\section{Introduction}

The foreign research about fund managers' stock selection ability and timing ability started earlier. Treynor and Mauzy (1966) [1] used an innovative way to regard unsystematic risk undertaken in the fund portfolio as a square function of the difference between the actual rate of return and the risk-free rate of return in each period, and put securities investment funds' stock selection ability into metering empirical analysis. The results showed that when the stock mutual funds' timing ability was not significant on the whole. Henriksson and Merton (1981) [2] simplify this model, where the introduction of dummy variables proposed two random variables model. Through the analtsis of 116 open-ended mutual funds in the United States between 1968 and 1980,they found only a few fund stock picking ability is significantly positive, while the timing ability of most funds was significantly negative. Chang and Lewellen (1984) [3] used linear transformation for the HM model .that was the establishment of a new CL equivalent model, which can specifically distinguish the value between bulls and bears. Empirical findings was that mutual funds do not have a good stock selection ability nor timing ability. Busse (1999) [4] used Wave analysis in investment funds' selection ability and timing ability, found there was not significant positive correlation between the rate of return and the volatility. Thus fund managers at the market volatility choose to reduce positions, and increase financial position when the market volatility subsides, which can result in high returns. When studying funds' selection ability and timing ability, Cornell (2007), Utete (2008) used the classification of product style to find the explanation of institutional investors' different performance in long-term and short-term strategy.

As for whether sun private equity fund managers have higher stock-picking ability, there is not yet formed the same conclusion. when Fuli Luo used 63 sunshine private funds in 2010 in empirical analysis, it showed that most of the sun private equity fund did not have a stock-picking ability, so did their timing ability . Some funds even dragged down performance due to poor timing ability. [7] Studies also indicated that both excitation modes of fund managers prediction and the market judgments were quite basic, public fund managers was slightly better (Zhao Johnson, 2011). [9] However, most scholars still believe that the sunshine private equity funds have a stronger ability to invest, outperforming the market. [6]After classified by managers' career in the past, the overall performance of the Department of public offering fund managers were best, followed by Brokerage department and the Department of Civil. After distinguishing timing ability and stock picking skills, no significant timing ability of Department of public offering and Brokerage department is discovered, but there is a strong stock-picking ability, while folk-based fund manager is just the opposite (Dao round, 2013) [8]; based on comparation of performance before and after switching to private funds, it was concluded that the fund managers changed to improve the overall 
investment, mainly increasing in timing capacity ,but the fund manager's stock picking ability switched to a slight decrease compared with before. After analysis in the personal characteristics of fund managers, managers who had investment research experience obtained better investment performance (Yan Wu, Xiong Hang, 2015). [5]

Most of the existing studies are based on the basic assumption of the data's normal distribution, without taking the randomness of the income of Fund into account, or just use a single model instead of different models for data processing, so it is difficult to make conclusions convincing. By reference of some research methods, this paper improve the above two aspects using TM-FF4 model, complemented with bootstrap analysis [10] and the probability of success method, which makes empirical analysis under the two kinds of incentive mechanism more forceful.

\section{The Model of the Investment Capacity and Test Assisted}

Model of the investment ability. We refer to relevant research scholars' work, combine the TM model and Carhart's (1997) four-factor model, and introduce the momentum of the abnormal factors $U M D_{\mathrm{t}}$ to form model TM-FF4:

$R_{\mathrm{i}, t}-R_{f, t}=\alpha_{p}+\beta_{1}\left(R_{m, t}-R_{f, t}\right)+\beta_{2}\left(R_{m, t}-R_{f, t}\right)^{2}+\beta_{t, S M B} S M B_{t}+\beta_{t, H M L} H M L_{t}+\beta_{t, U M D} U M D_{t}+\varepsilon_{p, t}$

$R_{\mathrm{i}, t}$ is the fund i's weekly yield rate at the end of the period. ${ }^{R_{\mathrm{m}, t}}$ is the market portfolio's weekly return rate ${ }^{R_{\mathrm{f}, t}}$ is the risk-free interest rate.$S M B_{\mathrm{t}}$ is the difference of the weekly yield rate between small capitalization stocks and large capitalization stocks, while $H M L_{t}$ between high carrying value stock and low carrying value stock, and $U M D_{\mathrm{t}}$ between high yields stock and low high yields stock. $\alpha_{p}$ and $\beta_{2}$ represent the fund manager's stock selection ability and timing ability respectively. If they are significantly greater than zero, the Fund manager has strong stock selection ability and timing ability, respectively, otherwise they will be poor.

Sub-test of Stock-Picking Ability. This paper uses bootstrap residuals analysis in sub-test of preliminary comparative results for stock picking ability. Randomly sampling residuals estimates obtained by the TM-FF4 model above of each fund, we can construct combination of a new pseudo excess return in time series .these combination assumes that the stock selection ability is zero (i.e. ${ }^{\hat{\alpha}_{p}}=0$ )

$\left(R_{i, t}-R_{f, t}\right)^{b}=\hat{\beta}_{1}\left(R_{m, t}-R_{f, t}\right)+\hat{\beta}_{2}\left(R_{m, t}-R_{f, t}\right)^{2}+\hat{\beta}_{t, S M B} S M B_{t}+\hat{\beta}_{t, H M L} H M L_{t}+\hat{\beta}_{t, U M D} U M D_{t}+\hat{\varepsilon}_{p, s}^{b}$

$\left(R_{i, t}-R_{f, t}\right)^{b}$ represents a pseudo excess rate of return, $\hat{\varepsilon}_{p, s}^{b}$ represents obtained in a random sample residuals(s and $t$ are used only to distinguish). Using the Pseudo excess returns in the new bootstrap sample to regression analysis, we can get $\alpha_{\mathrm{p}}^{b}$ which is not zero. Repeat this bootstrap process for each fund 1000 times. If only a few positive values $\alpha_{\mathrm{p}}^{b}$ are more than the actual data generated, it can be concluded that: the change of samples is not the reason for high ${ }^{\alpha_{p}}$, that is, the Fund's performance does not depend on luck but on stock picking ability. If most of the positive value ${ }^{\alpha_{\mathrm{p}}^{b}}$ are more than the actual data generated, it can be concluded that: the change of samples may be the reason for high ${ }^{\alpha_{p}}$, that is, the Fund's performance may depend on luck, and random samples may also have such gains.

Sub-test of Timing Ability. This paper uses success probability analysis in sub-test of preliminary comparative results for timing ability. Supposed that in the $\mathrm{n}$ quarters, the amount that fund has good performance is a, and the number of remaining quarters is (n-a). In the quarters that fund has good performance, the number that manager has positive timing ability is ${ }^{a_{1}}$, and In the quarters that fund has bad performance ,the number that manager has positive timing ability is $b_{1}$,so probability of success $P=\left(a_{1} / a+b_{1} /(n-a)-1\right)$.If $P$ is significantly greater than zero, it can be sure that the fund manager has excellent timing ability, whereas it can be inferred that the fund manager does not have good timing ability. 


\section{Data Processing and Analysis}

Sample Data and Data Process. We select 29 sunshine private funds' and 29 public offered funds' weekly yield rate from Wind database as the observed value, whose duration is not less than 5 years between 2010 and 2016 and use the R operating software for regression analysis. $R_{\mathrm{m}, t}$ is the Shanghai and Shenzhen 300 index's weekly returns. The central bank's adjusted weekly deposit interest rate is the risk-free interest rate .We choose the difference of weekly yield rate between tidal wave small-cap index and tidal wave yields value of the index's as the scale factor $S M B_{\mathrm{t}}$, between the full indicated value index and the full growth index as the value factor $H M L_{t}$ and between the $30 \%$ best performing stock in earlier period and the $30 \%$ worst stock as the momentum of the abnormal factors $U M D_{\mathrm{t}}$.

\section{The Empirical Results}

Comparison between Sunshine Private Equity Funds and Publicly Offered Fund'S Stock Selection Ability. As is shown in the Table 1, the average of sunshine private funds and public offered funds are -0.0087 and 0.0053 respectively. Among the 29 sunshine private equity funds, only 2 funds pass the test with the significance level of $10 \%$, while in the 29 publicly offered funds, most values are positive, only 6 funds are negative, and the only 5 funds and 3 funds pass the test with the significance level of $10 \%$ respectively. We can preliminarily conclude that sunshine private funds managers' stock selection ability is lower than public offered funds managers'. But the two fund's stock selection ability is not significant in statistics, and the conclusion remains to be tested.

Table 1 Regression results of stock selection ability based on TM - FF4

\begin{tabular}{c|c|c|c|c|c|c|c|c|c}
\hline funds & $\alpha$ & $\mathrm{t}$ value & $\mathrm{p}$ value & $\alpha>0$ & $5 \%$ level & $10 \%$ level & $\alpha<0$ & $5 \%$ level & 10\%level \\
\hline spef & -0.0087 & -0.2105 & 0.4609 & 11 & 0 & 2 & 18 & 2 & 2 \\
\hline pof & 0.0053 & 0.5944 & 0.3747 & 23 & 2 & 5 & 6 & 3 & 3 \\
\hline
\end{tabular}

Using the bootstrap method for further inspection on the above conclusion: we sample 100 times the residual error of each fund randomly, count when $\alpha_{\mathrm{p}}^{b}$ in the bootstrap method is greater than $\alpha_{p}$, then rank the amount of 29 funds as the top 20 in Table 2 . We find most of the ${ }^{\alpha_{\mathrm{p}}^{b}}$ about sunshine private funds through the generation of the bootstrap value is greater than the actual $\alpha_{\mathrm{p}}^{b}$, so the fund's performance is likely to due to luck, random sample can also produce such benefits. In the same way, we can get the opposite conclusion: only a handful of public offered funds $\alpha_{\mathrm{p}}^{b}$ obtained by the bootstrap method are greater than the actual $\alpha_{\mathrm{p}}^{b}$.It follows that although those public funds have no significant positive stock selection ability, the performance of public funds is not by chance but by its stock selection ability. Through the contrast, we say that the sunshine private funds managers' stock selection ability is lower than that of public offered funds managers. 
Table 2 The frequency statistics based on bootstrap method

\begin{tabular}{c|c|c|c|c|c}
\hline rank & spef & pof & rank & spef & pof \\
\hline 1 & 999 & 994 & 11 & 723 & 358 \\
\hline 2 & 982 & 991 & 12 & 689 & 292 \\
\hline 3 & 968 & 986 & 13 & 672 & 277 \\
\hline 4 & 932 & 757 & 14 & 607 & 276 \\
\hline 5 & 930 & 710 & 15 & 599 & 275 \\
\hline 6 & 925 & 645 & 16 & 560 & 235 \\
\hline 7 & 920 & 474 & 17 & 517 & 150 \\
\hline 8 & 898 & 418 & 18 & 516 & 144 \\
\hline 9 & 768 & 399 & 19 & 398 & 103 \\
\hline 10 & 729 & 381 & 20 & 348 & 100 \\
\hline
\end{tabular}

\section{Comparison between Sunshine Private Equity Funds and Publicly Offered Fund's Timing}

Ability. As found in Table 3 based on TM - FF4 model, average of $\beta_{2}$ sunshine private funds and public offered funds are $0.0572,0.0147$ respectively. In the two groups of funds, most of the value is positive, and only a handful of fund's value is negative. In the right value, 6 founds pass the test with significance level of $10 \%$.Sunshine private funds with negative values don't not pass it, while only one of public offered funds with negative values do it . Thus we can preliminarily concluded that sunshine of private funds managers' timing ability is only marginally better than public offered funds managers. But these timing ability are not significantly statistical, which still need to be tested.

Table 3 Regression results of timing ability based on TM - FF4

\begin{tabular}{c|c|c|c|c|c|c|c|c|c}
\hline funds & $\beta 2$ & $\mathrm{t}$ value & $\mathrm{p}$ value & $\beta 2>0$ & $5 \%$ level & $10 \%$ level & $\beta 2<0$ & $5 \%$ level & $10 \%$ level \\
\hline spef & 0.0572 & 0.8859 & 0.3774 & 24 & 2 & 6 & 5 & 1 & 0 \\
\hline pof & 0.0147 & 0.7340 & 0.3966 & 23 & 3 & 6 & 6 & 1 & 1 \\
\hline
\end{tabular}

Using the successful probability method for further inspection on the above conclusion: rank the success probability of the two groups in descending order respectively, as the top 20 statistical data is shown in Table 4.

We find the success probability of sunshine private funds are significantly higher than that of public offered funds.so a further conclusion can be get: Private equity funds managers' timing ability is higher than that of public offering funds managers.

Table 4 Results of success probability statistics

\begin{tabular}{c|l|l|r|r|l}
\hline rank & spef & \multicolumn{1}{|c|}{ pof } & rank & \multicolumn{1}{l}{ spef } & pof \\
\hline 1 & 0.1495 & 0.0825 & 11 & 0.0304 & -0.0011 \\
\hline 2 & 0.1412 & 0.0763 & 12 & 0.0260 & -0.0085 \\
\hline 3 & 0.0775 & 0.0461 & 13 & 0.0230 & -0.0100 \\
\hline 4 & 0.0765 & 0.0256 & 14 & 0.0186 & -0.0166 \\
\hline 5 & 0.0706 & 0.0182 & 15 & 0.0044 & -0.0166 \\
\hline 6 & 0.0569 & 0.0097 & 16 & -0.0054 & -0.0174 \\
\hline 7 & 0.0544 & 0.0085 & 17 & -0.0064 & -0.0190 \\
\hline 8 & 0.0500 & 0.0039 & 18 & -0.0074 & -0.0213 \\
\hline 9 & 0.0382 & 0.0012 & 19 & -0.0103 & -0.0329 \\
\hline 10 & 0.0333 & 0.0004 & 20 & -0.0132 & -0.0499 \\
\hline
\end{tabular}




\section{Summary}

This article mainly uses the TM - FF4 model to compare the selectivity ability and market-timing ability of sunshine private funds with publicly offered founds, and then use the method of the bootstrap and probability of success respectively as auxiliary inspection. Although both of fund managers' investment ability is statistically insignificant, we can get a consistent conclusion: sunshine private fund managers' timing ability is only marginally better than publicly offered fund managers', but their stock selection ability is much less than that of the publicly offered fund managers.

At this stage, we should strengthen the professional talent training, standardize the investment decisions, perfect the regulation system, in order to improve the internal management mechanism, so as to promote the overall improvement of the investment capacity of sunshine private equity fund managers .To improve the timing ability of public offered funds managers, we are supposed to add the salary incentive factors, and fresh impetus into for more active investment, which can arouse public offered fund managers to timely control positions and maintain the potential of strategic flexibility.

\section{References}

[1] J.L. Treynor and K. Mazuy: Harvard Business Review, Vol. 44 (1996) No.5,p.131-136.

[2] R.D. Henriksson and R.C. Merton: Journal of Business, Vol. 54 (1981) No.4,p.513-533.

[3] E.C. Chang and W.G. Lewellen. Market: Journal of Business, (1984) No.1,p.57-72.

[4] Jeffrey .A. Buss: Review of Financial Studies,(1999) No.5,p.1009-1041.

[5] W. Yan and H. Xiong: Contemporary Finance \& Economics, (2015)No.7,p.45-56.(In Chinese)

[6] Q.H. Li and C.Q. Ma: Financial Research, (2004) No.7,p.56-65. (In Chinese)

[7] F.L. Luo: Economic BBS. (2012) No.2,p.106-107.(In Chinese)

[8] D.L. Chen, X. Chen, G.M. Chen and X.Y. Zhang: Financial Research,(2013)No.12,p.85-99.(In Chinese)

[9] J. Zhao and G.H. Chen: Pioneering with Science \& Technology Monthly, (2011) No.17,p.42-45.(In Chinese)

[10]Y. Wang and X.M. Zhang: China Soft Science, (2013) No.11,p.139-150.(In Chinese) 